40

TOM, SIBLING RELATIONSHIP, AND PARENTING

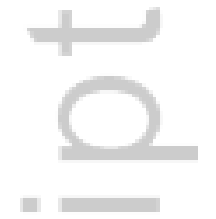

Theory-of-Mind Development and Early Sibling Relationships after the Birth of a Sibling: Parental Discipline Matters

\author{
Ju-Hyun Song \\ University of Toronto \\ Brenda Volling \\ University of Michigan
}

Author Note

Ju-Hyun Song, Department of Psychology, University of Toronto, Canada; Brenda L. Volling, Center for Human Growth and Development, Department of Psychology, University of Michigan, U.S.A.

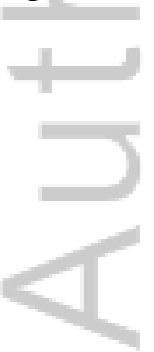

This is the author manuscript accepted for publication and has undergone full peer review but has not been through the copyediting, typesetting, pagination and proofreading process, which may lead to differences between this version and the Version of Record. Please cite this article as doi: 10.1002/icd.2053

This article is protected by copyright. All rights reserved. 
Song Ju-Hyun (Orcid ID: 0000-0002-7264-4732)

40

TOM, SIBLING RELATIONSHIP, AND PARENTING

The research was supported by grants (R01HD042607, K02HD047423) from the Eunice

Kennedy Shriver National Institute of Child Health and Human Development to Brenda L.

Volling. We are grateful for the participation of the families of the Family Transitions Study.

Correspondence concerning this article should be directed to Ju-Hyun Song, 3359 Mississauga

= Road, Mississauga, ON L5L 1C6, Canada, Email: juhyun.song@utoronto.ca
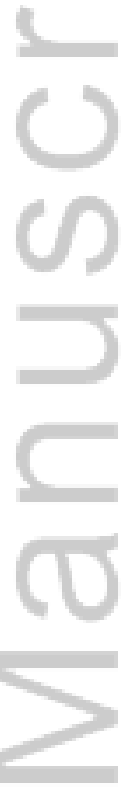

Keywords: theory-of-mind, sibling relations, parental discipline 
40

TOM, SIBLING RELATIONSHIP, AND PARENTING

Theory-of-Mind Development and Early Sibling Relationships after the Birth of a Sibling:

\section{Parental Discipline Matters}

Theory-of-Mind (ToM) is a child's ability to understand that people can have different desires, knowledge, and beliefs, and that actions are often a product of these mental states (Harris, 2006; Wellman, 2014). This fundamental social-cognitive skill underlies children's competencies to build social relationships even in the early years of life and is associated with higher levels of prosociality and fewer antisocial behaviors beyond childhood (Hughes, 2011). Most children acquire basic ToM understanding by age 6 (e.g., false belief; Wellman \& Liu, 2004), yet there are individual differences in the pace of development during toddlerhood and the preschool years. The quality of sibling relationships and parent-child relationships is closely associated with these individual differences (Dunn, Brown, Slomkowski, Tesla, \& Youngblade, 1991; Hughes, 2011, Peterson, 2000), but few studies have attempted to understand how both sibling relationships and parenting actively contribute to developing ToM (Song, Volling, Lane, \& Wellman, 2016; Peterson, 2000). When studies examine the relation between ToM and social relationships, most are cross-sectional rather than longitudinal, making it difficult to understand the directionality of associations (Cutting \& Dunn, 1999; Hughes \& Ensor, 2005).

The period between 2 and 3 years of age is formative for social cognitive development, and is also a time when many children experience the birth of a sibling (Baydar, Greek, \& Brooks-Gunn, 1997). Dunn and Kendrick (1982) reported a sharp increase in children's discussions of the self and other (i.e., baby) when the sibling was born, underscoring the 
potential impact of the arrival of a sibling on children's social-cognitive understanding. There are individual differences in how children react to the arrival of a baby sibling and these individual differences are linked to children's temperament and social understanding (Song \& Volling, 2015; for a review, see Volling, 2012). The present longitudinal study examined the associations between firstborn children's ToM development, the quality of their interactions with an infant sibling, and parental discipline during the first year after the birth of a sibling. We refer to the firstborns as children and the infants as siblings in the remainder of this paper.

\section{Sibling Relationships and ToM Development}

Children with siblings appear to perform better on ToM tasks than children without siblings (Jenkins \& Astington, 1996; Peterson, 2000). The sibling relationship, it seems, is a powerful socializing context for children's ToM development for both older and younger siblings in a number of ways (Dunn, 2008), although the existing literature has focused mostly on how younger siblings benefited from having an older sibling. First, children involved in more positive sibling interactions_-cooperative or joint pretend play—have better ToM understanding (Dunn et al., 1991). When children engaged in cooperative interactions with an older sibling in toddlerhood, they outperformed their peers on ToM tasks during the preschool years (Dunn et al., 1991). Hughes (2011) also reported that siblings often referred to mental states and aligned their viewpoints during enjoyable and positive sibling interactions. Further, children were more likely to discuss roles, co-construct fantasy scenes, and use mental-state language during episodes of joint pretend play with their siblings (Howe, Petrakos, \& Rinaldi, 1998). Such 
positive exchanges with one's sibling require that children consider another's perspective and the consequences of their own and others' mental states, which may, in turn, contribute to ToM growth (Hughes, 2011). With respect to the transition to siblinghood, Dunn and Kendrick (1982) found that children were more likely to show positive interest in and affection toward their 8month-old infant sibling when mothers referred to the infant as a person and emphasized the joint responsibility of mother and child in caring for the infant during the first weeks after the birth. Thus, conversations focused on the child and the infant may be conducive to positive sibling interactions, as well as social cognitive understanding of others' emotions and minds (Randell \& Peterson, 2009; Slomkowski \& Dunn, 1992).

Sibling conflict is the second way that sibling interactions contribute to children's ToM development. Dunn (1988) suggested that the opposition and different viewpoints expressed during daily conflicts between siblings and their parents contributed to their understanding of others' emotions and minds. Moreover, conflicts often elicited the mentalistic conversations (e.g., talking about the causes of negative emotions) between parents and children that can be conducive to the development of ToM (Lagatutta \& Wellman, 2002). The first aim of the current report was to examine the longitudinal, reciprocal relations between children's ToM and both their positive and antagonistic interactions with their infant sibling throughout the year following the sibling's birth. Few studies have focused on early sibling interactions after the birth of a sibling, a time when discussions about the newborn sibling between the child and parents are frequent (Dunn, 1988). Many ToM studies focus on sibling relationships with preschool-age 
younger siblings, when both siblings are verbal and can actively participate in reciprocal interactions (e.g., Dunn et al., 1991; Foote \& Holmes-Lonergan, 2003; Howe et al., 1998). Yet, Peterson (2000) reported that preschool-age older siblings with an infant sibling showed more advanced ToM understanding compared to only children without siblings or children with an adolescent sibling, suggesting that the presence of an infant sibling may provide opportunities for interactions that contribute to ToM development. In the current study, we focused on how older siblings benefit from having a younger sibling and anticipated that children's greater ToM understanding before their sibling's birth would predict more positive interactions with the infant sibling, which would, in turn, enhance ToM development over time.

\section{Parental Discipline and ToM Development}

With respect to conflict with the infant, we went one step further and considered the role of parental discipline, believing that how parents responded to children's antagonistic interactions with the infant would moderate the effect of sibling antagonism on the development of ToM. Prior research suggested that sibling conflict was either positively or negatively related to ToM development depending on the affective tone and destructive nature of the conflict, as well as how parents managed it (Foote \& Holmes-Lonergan, 2003; Slomkowski \& Dunn, 1992; Randell \& Peterson, 2009). In the present research, we considered how parents engaged children during potential conflict with the infant sibling and whether they used child-centered (e.g., reasoning about how the child's behavior can affect the sibling's feeling) or parent-focused (e.g., punishing the child with love-withdrawal) discipline. In an earlier report, we found that 
children's aggressive behavior problems before the birth of a sibling predicted increased antagonistic behaviors toward the infant sibling after the birth, and that children's poor ToM at 4 months after the birth predicted increased sibling antagonism by 12 months (Song et al., 2016). In explaining what might account for relations between ToM and sibling antagonism after the birth of a sibling, we suggested that caregivers must play some role in facilitating children's early interactions with the infant sibling, who is too young to engage the older sibling in the early months. Further research is necessary to determine whether parental involvement and the type of discipline used to respond to sibling conflicts contribute to children's ToM development and sibling relationships. How parents respond to potential conflict between children and their infant siblings and the discipline they dispense may give rise to different conversations between parents and children about moral rules, the proper conduct of behavior, and the consideration of other's emotions. Thus, the second aim was to examine the moderating role of parental use of childcentered discipline emphasizing inductive reasoning and conversation with the child versus parent-centered discipline focusing on constraining child misbehaviors when modeling the longitudinal relations between ToM and sibling antagonism.

Child-centered, inductive discipline that focuses on the infant sibling's feelings during conflict episodes may provide fruitful opportunities for children to learn about others' minds (Hughes, 2011). When mothers viewed sibling conflicts as constructive, as opposed to destructive, preschool-age children were more likely to show positive affect during sibling debate, which was positively associated with greater ToM understanding (Randell \& Peterson, 
2009). These findings provide preliminary evidence for the potential moderating role of parental discipline in explaining relations between sibling conflict and children's ToM. In the current study, we hypothesized that when parents used low levels of child-centered discipline (e.g., talking through solutions with the child), or high levels of parent-centered, punitive discipline (e.g., scolding or threatening the child) in conflict situations, children would be less likely to benefit from sibling conflict for acquiring ToM understanding. Punitive and controlling strategies suppress children's emotional expression and may undermine the development of children's social understanding by curtailing children's opportunities to regulate negative emotions and to learn about the self and other (i.e., sibling) in sibling conflict contexts (Dunn \& Kendrick, 1982; Perozynski \& Kramer, 1999).

Parent responses to children's negative interactions with the infant may be especially important for ToM development during the transition to siblinghood because young children are not yet socially adept at interacting with their infant sibling without adult assistance. How parents respond may affect whether children focus on internal states of self and the infant, or not. Further, most studies have focused exclusively on mothers' behavior and have not taken into account the role of fathers for children's ToM development. In fact, fathers' discipline may be particularly influential after the birth of a sibling because mothers are largely preoccupied with caring for the infant and fathers may be spending more time with firstborn children (Kreppner, Paulsen, Schuetze, 1982; Volling \& Belsky, 1992). In the current report, we examined both 
maternal and paternal disciplinary strategies with children and how they predicted ToM and sibling interaction.

\section{The Present Study}

The present study examined the associations among firstborn children's ToM development, early interactions with an infant sibling, and mothers' and fathers' discipline in response to children's misbehavior in the year following the birth of an infant sibling. The first aim was to examine the direction of effects between ToM and sibling interaction using a longitudinal, repeated measures, design. The second aim was to examine how parent-centered and child-centered parental discipline moderated the associations between sibling interactionantagonistic interaction, in particular_and ToM development. Children's reactive temperament was also included as a prenatal contributing factor for early sibling interactions in the models given prior research finding strong associations between children's negative emotionality and negative sibling interaction (Brody, 1998; Dunn et al., 1981). We hypothesized that children's high ToM understanding and low negative reactivity before the birth of a sibling would predict more positive engagement and less antagonism with the infant sibling over the course of the first year. Additionally, we expected sibling antagonism would predict poorer ToM when parents used less child-centered or more parent-centered discipline. We expected that both maternal and paternal discipline would have a moderating effect on children's interactions with the sibling and ToM development, given earlier suggestions of the importance of father involvement after the birth of a sibling (Kreppner et al., 1982; Volling \& Belsky, 1992). 


\section{Methods}

\section{Participants}

Families were part of a longitudinal study of firstborn children's adjustment after the birth of a second child. Initially, 241 mothers pregnant with their second child, living in the midwestern U.S., were recruited through obstetric clinics, local hospitals, childcare centers, pediatricians' offices, and child-birth education classes, and through local printed media targeting parents. Recruitment criteria required that the biological father of the infant was resident in the home, firstborn children were between 1 and 5 years at the time of the birth of the infant, infants were born full-term, and both children had no mental or physical developmental delays. Firstborn children were on, average, 2.5 years old $(M=31$ months; $S D=10$ months $)$ when the infant sibling was born. Mothers and fathers were primarily white (86\%) with $14 \%$ representing other racial and ethnic minorities. Most families were middle-class, earning $\$ 60,000$ - \$99,999 per year, with the majority of parents having a Bachelor's degree or above.

In order to reduce the wide age-gap among children due to the age-sensitive ToM measure used in this report, we included the 208 firstborn children who were 18 - 47 months old at the prenatal visit $\left(M_{\text {age }}\right.$ at prenatal $=29.74$ months; $M_{\text {age }}$ at 12 months $=43.49$ months; $S D=$ 7.69 months; 117 girls), so that children were less than 5 years old at 12 months. This age range was chosen because studies have shown that 18-month-old infants show early signs of understanding others' mental states (Meltzoff, 1995; Rapacholi \& Gopnik, 1997), and typically developing children achieve false-belief and hidden emotion tasks by age 5 (Wellman, 2014). 
Age breakdowns at the prenatal timepoint included 53 children between 18-23 months, 97 children between 24-35 months, and 58 children between $36-47$ months.

Among the 208 families included in analyses, the percentages of missing data for all study variables ranged from $0 \%$ to $17.8 \%(M=13.5 \%)$. Little's $(1988)$ Chi-square Test of MCAR revealed that the data were missing completely at random, $\chi^{2}(177)=200.75, p=.11$. Missing data were handled with full information maximum likelihood (FIML) estimation (Enders \& Bandalos, 2001) using AMOS, Version 22. Families $(N=208)$ included in the current analyses did not differ significantly from the original recruited sample $(N=241)$ on most of the demographic indicators (i.e., family income, parents' race/ethnicity, age, years of marriage, or siblings' gender). The one exception was mothers' education; mothers included in analyses had significantly higher education levels than those initially recruited, $\chi^{2}(2)=8.43, p<.05$.

\section{Design and Procedures}

The longitudinal project consisted of five time points: prenatal (the last trimester of the mother's pregnancy with the second child) and 1, 4, 8, 12 months after the birth of the second child. At each time point, information about children's behavioral adjustment and family interactions was collected using observations, interviews, and questionnaires during home visits. In the original project, ToM assessments were conducted at prenatal, 4, and 12 months, and parental reports of discipline in response to misbehavior directed at the infant sibling and sibling interactions were collected starting at 4 months. In the current study, we used mother- and fatherreports of children's interactions with the infant sibling at 4 and 8 months, and children's ToM at 
the prenatal and 12-month time points for modeling purposes. This was to ensure at least a year between ToM assessments and that ToM was measured before (prenatal) and after (12 months) sibling interactions were measured (4 and 8 months). Mothers' and fathers' discipline styles in response to children's misbehavior toward the sibling at 4 and 8 months were tested as moderators of this structural model in an effort to examine whether timing of parental discipline mattered in the first year. As covariates, we measured children's verbal IQ when ToM was measured, mothers' and fathers' education, and the infant sibling's difficult temperament at 1 month.

\section{Measures}

Theory-of-mind. Children's social understanding was measured with six ToM tasks developed by Wellman and Liu (2004) that most children master in sequence before age 6 (The six tasks were presented in the following order). For each task, children were shown a vignette and were asked questions: In the diverse desires task, children were asked to judge whether two persons (the child vs. someone else) had different desires about the same objects. In the diverse beliefs task, children had to judge how people (the child vs. someone else) might have different beliefs about the same object, when the child did not know which belief was true or false. In the knowledge access task, children saw what was in a box and judged (yes-no) the knowledge of another person who had not seen what was in a box. In the explicit false-belief task, children judged how someone would search, given the person's mistaken belief, and in the contents falsebelief task, children judged another person's false belief about what was in a distinctive container 
when the child knew what it actually was. Lastly, the hidden emotion task tested whether children understood that a person might feel one thing but display a different emotion. A total score was computed by summing the number of tasks the children answered correctly reflecting their understanding of others' desire, belief, or emotion. These ToM tasks form a Guttman Scale and have been widely used in different countries and across sub-populations (e.g., typically developing children, children with deafness) to capture variations in the progression of children's ToM development (Peterson, Wellman, \& Slaughter, 2012).

Given that ToM measures are highly age-sensitive during these early years (Wellman, Cross, \& Watson, 2001), assessing ToM using the same measure over time can be challenging, and several studies have used different age-appropriate ToM measures at different timepoints (e.g., Adrián, Clemente, \& Villanueva, 2007; Fink, Begeer, Hunt, \& de Rosnay, 2014). Consistent with prior studies, we calculated ToM scores taking into account the age range of children at each timepoint and reducing the positive skewness in ToM scores (Song et al., 2016). Specifically, ToM scores were calculated by summing the first three tasks (pre-false belief tasks: diverse desires, diverse beliefs, knowledge access) for the prenatal time points (ToM score ranged from 0-3 tasks passed) because most children (75\%) were still under age 3 at this time and too young to pass false-belief and hidden emotion tasks (Wellman \& Liu, 2004). At 12 months, all six tasks were used (ToM score ranged from 0-6) when 80 percent of children were between 36 months and 59 months (see Song et al., 2016 for similar strategy). 


\section{Interactions with infant sibling. The Sibling Relationships in Early Childhood scale}

(Volling \& Elins, 1998) was used to measure children's interactive behaviors toward the infant sibling at 4 and 8 months. Mothers and fathers were asked to rate firstborn children's behaviors toward the infant on a 5 -point Likert scale $(1=$ almost never $; 3=$ sometimes $; 5=$ almost always $)$, yielding subscales of positive engagement (e.g., initiates play or interactions with baby, 7 items, $\alpha=.84-.85$ ), antagonism (e.g., is physically aggressive with baby, 5 items, $\alpha=.74-.75$ ), and avoidance (e.g., stays away from baby if possible, 3 items, $\alpha=.56-.67$ ). Because of the lower internal consistency of the avoidance scale, only positive engagement and antagonism were included in the current analyses. Mothers' and fathers' reports were used as indicators for latent factors.

Parental discipline in response to children's misbehavior. At 4 and 8 months, The Managing Children's Conflict Questionnaire (Perozynski \& Kramer, 1999) was modified to assess parents' responses to firstborn children's negative interactions with their infant sibling. Mothers and fathers were asked to use a 3-point Likert scale $(1=$ almost never, $2=$ sometimes, 3 = usually) to rate how often they used each of the possible management strategies in response to children's misbehavior toward the infant sibling in the past month. The measure yielded two subscales: child-centered discipline (e.g., asked the child to explain their side and worked with them to reach a solution, 4 items, $\alpha=.70-.73$ ) and parent-centered discipline (e.g., told my older child that s/he would be punished if s/he did not stop misbehaving, 9 items, $\alpha=.74-.77$ ). Child-centered discipline refers to a responsive discipline strategy directing the child to solve 
problems, reason, and negotiate through communication. In contrast, parent-centered discipline focused on the parent's own distress and needs, with the goal of decreasing the child's misbehavior through punitive behaviors or passive nonintervention.

Negative reactivity. At the prenatal time point, both parents reported on children's temperamental characteristics using two scales of the Child Behavior Questionnaire (CBQ; Rothbart, Ahadi, \& Hershey, 1994) on a 7-point Likert scale ranging from 1 (extremely untrue) to 7 (extremely true): (a) soothability (13 items, $\alpha=.75-.77$ ) measured the rate of recovery from peak distress, excitement, or general arousal (e.g., "If upset, cheers up quickly when s/he thinks about something else") and (b) anger (13 items, $\alpha=.73-.77$ ) assessed the amount of negative affect related to goal blocking (e.g., "Has temper tantrums when s/he doesn't get what s/he wants"). Soothability and anger were significantly correlated, $r=-.51$ for mothers and $r=-.42$ for fathers, $p<.01$. A negative reactivity score was created by subtracting children's soothability from their anger score to create separate scores for mothers and fathers. Mothers' and fathers' reports were used as indicators for a latent factor.

Covariates. We included the child's age as a covariate because ToM is an age-sensitive measure (Wellman, 2014) and sibling relationship quality may be affected by children's age (McHale, Updegraff, \& Whiteman, 2012; Volling, 2012). We also included children's gender because of earlier research finding differences in affective understanding between boys and girls (Dunn et al., 1991). Parents' education (i.e., mother's and father's highest degree earned) was also included based on the well-established literature linking it to parenting quality (Davis-Kean, 
2005) and children's ToM development (Pears \& Moses, 2003). Additionally, verbal IQ and infants' difficult temperament were included as covariates because of evidence suggesting that children's verbal IQ is positively correlated with ToM performance (Carlson \& Moses, 2001) and the younger siblings' difficult temperament is related to poorer sibling relationship quality starting in early childhood (Brody, 1998).

Verbal IQ. At the prenatal time point and at 12 months (i.e., when ToM was assessed), children's verbal IQ was measured with the receptive vocabulary subscale of the Wechsler Preschool and Primary Scale of Intelligence, Third Edition (WPPSI-III; Wechsler, 2002). Verbal IQ at both time points was included as covariates in ToM analyses.

Infants' difficult temperament. The infant sibling's difficult temperament was assessed with the fussy-difficult subscale of the Infant Characteristics Questionnaire (ICQ; Bates, Freeland, \& Lounsbury, 1979) at 1 month. Both mothers and fathers rated their infants' behaviors on a 7-point Likert scale ranging from 1 (very easy) to 7 (difficult). The fussy-difficult subscale included items such as "How easy or difficult is it for you to calm or soothe your baby when he/she is upset?" (9 items, $\alpha=.83-.87$ ). Mothers' and fathers' reports were highly correlated $(r=.54, p<.01)$ and averaged to create a robust composite.

\section{Analysis Overview}

After examining correlations among the study variables, we used structural equation modeling (SEM; Kline, 2011) to test our measurement model and create latent variables using mothers' and fathers' reports as indicators for child temperament (i.e., negative reactivity at the 
prenatal time point) and sibling interactions (i.e., positive engagement and antagonism at 4- and 8 months). To test for the longitudinal relations between ToM and sibling interactions, structural equation models were built and tested in steps (i.e., nested) that took into consideration the developmental timing of when children initiated conflict and their parents intervened. In a prior report from this investigation, Oh, Volling, \& Gonzalez (2015) found that most children were positively engaged in sibling interactions in the year after the birth $(50 \%)$, but a small percentage $(8 \%)$ initiated antagonistic interactions with their infant sibling as early as 4 months. Further, a substantial number (42\%) showed an escalation in sibling antagonism from 4 to 12 months. These results suggested that timing ( 4 or 8 months) may be critical for both assessing sibling interaction and parental discipline, so we also considered timing in testing relations between ToM, sibling interactions, and parental discipline. Model 1 (stability-cross-lag) required that children's ToM and temperament before the birth of a sibling predicted sibling antagonism and positive sibling interaction at 4 months that then remained stable to 8 months, which, in turn, predicted 12-month ToM. Model 1 also included the cross-lag paths between positive and antagonistic sibling interactions to test the bidirectional associations between positive and negative sibling interaction over time while controlling for the stability of each type (see solid lines in Figure 1). By predicting 4-month sibling antagonism from prenatal indicators in Model 1, however, we may only be predicting sibling antagonism for the small risky group of children engaged in early-onset sibling antagonism (see Oh et al., 2015), and may not be capturing relations indicative of the larger group of children showing increases in antagonism later in the 
year. Thus, we may be missing the full effect of ToM on sibling interaction as it unfolded from 4 to 8 months. Therefore, Model 2 (increasing sibling antagonism and engagement) tested the direct effects of ToM on the escalation of antagonism and change in positive sibling engagement by adding paths from pre-birth ToM and temperament to 8-month sibling interactions (see dashed lines in Figure 1). Finally, Model 3 (early sibling influence) added the direct paths from 4-month sibling interactions to the prediction of 12-month ToM (see dotted lines in Figure 1) to test whether these early sibling interactions at 4 months added to the prediction of ToM. We used the chi-square difference test to compare model fit across the three models.

To test our second aim, we examined mothers' and fathers' discipline strategies in response to sibling conflict as a moderating variable for the ToM-sibling interaction paths. We reasoned that developmental timing may be important when assessing parental intervention into sibling conflict given that sibling antagonism was more frequent at 8 months when infants were more active social partners than at 4 months when they were relatively immobile and limited in their social engagement (Oh et al., 2015). Thus, parental discipline occurring at 8 months may reflect a more consistent and frequent pattern of child-centered versus parent-centered discipline than that occurring at 4 months. To test this specifically, we ran two series of moderation models, one using parent reports of discipline at 8 months and another using reports at 4 months, expecting the moderation effect would be stronger using 8-month measures. Separate models were run for mothers and fathers' discipline, and for child-centered discipline and parentcentered discipline, to maintain parsimony and address their distinctive effects. We used a multi- 
group modeling strategy to test whether the associations between sibling interaction and ToM differed significantly across families using high and low levels of child-centered and parentcentered discipline. In line with prior work (Lee, Lee, \& August, 2011; Vélez, Wolchik, Tein, \& Sandler, 2011), we calculated median splits to divide mothers and fathers into high and low groups of child-centered, $M d n$ for mothers and fathers $=1.68$ at 4 months, 2.00 at 8 months, and parent-centered discipline, $M d n$ for mothers $=1.57$ at 4 months and 1.78 at 8 months; for fathers $=1.45$ at 4 months and 1.67 at 8 months. Both unconstrained (paths were allowed to vary across high and low groups) and constrained models (all paths were constrained to be equal) were conducted. A significant omnibus chi-square difference test between the constrained and unconstrained models assesses whether path coefficients differed across high and low discipline groups. If an omnibus chi-square difference was significant, then each individual path was constrained to be equal across the two groups one at a time to test whether it resulted in a significant chi-square difference in order to determine which paths were indeed different across the high and low discipline groups.

AMOS Version 22 (Arbuckle, 2013) with maximum likelihood estimation was used for testing all measurement and structural equation models. Multiple fit indices including the comparative fit index (CFI; > .95 for good fit; > .90 for moderate fit), Tucker Lewis index (TLI; $>.95$ for good fit; > .90 for moderate fit) and the root mean square error of approximation (RMSEA; <.06 for good fit; <.08 for moderate fit) were used to evaluate the fit of each model 
(Hu \& Bentler, 1999; McDonald \& Ho, 2002). The $\chi^{2}$ test of significance is reported, but not used as a measure of model fit because it is highly sensitive to sample size (Kline, 2011).

\section{Results}

\section{Preliminary Analyses}

Descriptive statistics and correlations between variables are shown in Table 1 for mothers' and fathers' reports separately. Notable is the cross-time stability in children's ToM performance from before to one year after the birth. Correlations across parents for sibling interactions and temperament were significant, supporting the rationale for creating latent constructs using mothers' and fathers' reports for our SEM models. Positive sibling engagement and sibling antagonism were uncorrelated, providing further support for including them as two separate latent constructs in our SEM models. Child-centered and parent-centered discipline were both positively related to sibling antagonism and were positively correlated with one another for both mothers and fathers.

Measurement model. Before examining the primary structural models, measurement models were tested to check whether manifest variables cohered to form the anticipated latent constructs of interest. The measurement model included five latent constructs: children's negative reactivity at the prenatal time point, positive sibling engagement at 4 and 8 months, and sibling antagonism at 4 and 8 months. Mothers' and fathers' scores were used as indicators for each of the latent constructs. Correlations among the latent factors were estimated and unique variances within parent were allowed to covary when suggested by the modification indices. The 
measurement model fit the data moderately well, $\chi^{2}(23, N=208)=45.16, p<.01, \mathrm{CFI}=.96$, $\mathrm{TLI}=.90, \mathrm{RMSEA}=.07(90 \% \mathrm{CI}=.03-.09)$. Model estimated loadings for the indicators were all significant in the expected direction. Standardized loadings for the indicators of all latent variables ranged from .44 to $.92, p s<.001$, and variances of all latent variables ranged from .07 to $.33, p s<.01$.

\section{Longitudinal Relations and Timing of Effects between ToM and Sibling Interactions}

We tested the longitudinal relations between children's ToM and sibling interactions, expecting children's advanced ToM before the birth of a sibling would predict more positive and less antagonistic sibling interactions after the birth that would then predict children's ToM at one year (see Model 1 in Figure 1). Model 1 assessing the stability and cross-lag relations (i.e., indirect paths) over time fit the data moderately well, $\chi^{2}(124, N=208)=180.3, p<.01$, CFI $=$ $.94, \mathrm{TLI}=.92, \mathrm{RMSEA}=.05(90 \% \mathrm{CI}=.03-06)$. The chi-square, however, significantly improved (decreased) from Model 1 to Model 2, $\Delta \chi^{2}(4)=12.6, p<.05$, and Model 2 predicting changes in sibling interaction fit the data well, $\chi^{2}(120, N=208)=167.7, p<.01, \mathrm{CFI}=.95$, TLI $=.93, \mathrm{RMSEA}=.04(90 \% \mathrm{CI}=.03-.06)$. Model 3 examining early sibling influence also fit the data well, $\chi^{2}(118, N=208)=167.5, p<.01, \mathrm{CFI}=.95, \mathrm{TLI}=.92, \mathrm{RMSEA}=.05(90 \% \mathrm{CI}=.03$ - .06), but the model fit did not improve significantly when comparing Model 2 to Model $3, \Delta \chi^{2}$ (2) $=0.2, n s$; thus, Model 2 was chosen as the final model (see Figure 2).

Figure 2 shows the significant paths for Model 2. Prenatal ToM positively predicted ToM at 12 months and more positive sibling engagement at 4 months. Children's negative 
reactivity positively predicted higher antagonism at 4 months and increases in antagonism as well as decreases in positive sibling engagement from 4 to 8 months. Individual differences in both sibling antagonism and positive sibling interaction were highly stable from 4 to 8 months in general, as indicated by the significant autoregressive paths. In summary, the nested model comparison results suggested that pre-birth indicators of children's negative reactivity and ToM predicted early sibling interaction quality at 4 months, as well as changes in the levels of antagonism and positive engagement from 4 to 8 months (Model 2), better than either the stability-cross-lag (Model 1) or early sibling influence (Model 3) models. As a result, we used Model 2 in our multi-group analysis to test the moderating role of parental discipline.

\section{Moderating Effects of Parental Discipline}

Our second goal was to examine whether parental discipline moderated the links among sibling interaction during the year and ToM. Specifically, we hypothesized that sibling antagonism would be positively related to ToM at 12 months when parents used high levels of child-centered discipline or low levels of parent-centered discipline, but would be negatively related to ToM when parents used more parent-centered discipline or low child-centered discipline. We also tested these models using parental discipline first at 4 months and then a second set of moderation models using 8-month indicators of parental discipline to determine if timing of discipline mattered for determining these relations.

Omnibus chi-square difference tests between the constrained and unconstrained models revealed that only mothers' child-centered discipline at 8 months was a significant moderator, 
$\Delta \chi^{2}(33)=54.3, p<.05 .{ }^{1}$ Figure 3 shows standardized path coefficients for the low and high maternal child-centered discipline groups revealing three with significantly different paths: (a) from 4-month sibling antagonism to 8-month sibling antagonism, $\Delta \chi^{2}(1)=5.4, p<.05$, (b) from 8-month sibling antagonism to 12 -month ToM, $\Delta \chi^{2}(1)=4.0, p<.05$, and (c) from prenatal negative reactivity to 8 -month sibling antagonism, $\Delta \chi^{2}(1)=4.6, p<.05$. Specifically, children in the low maternal child-centered discipline group had higher stability in antagonism from 4 to 8 months, and 8-month sibling antagonism negatively predicted 12-month ToM, which was not the case for children whose mothers used high child-centered discipline. Also, children's negative reactivity predicted increases in sibling antagonism from 4 to 8 months, but only in the families in which mothers used high child-centered discipline. Child-centered discipline at 4 months was not a significant moderator for either mothers or fathers.

Neither mothers' nor fathers' parent-centered discipline at either 4 or 8 months moderated the links between children's ToM and sibling interaction in the year following the birth of an infant sibling.

\section{Discussion}

Depending on the way children interpret their experiences with the infant sibling and communicate with parents about the infant's desires and needs, the presence of a sibling may have different consequences for children's social-cognitive development. To understand these processes, the current study examined the longitudinal associations between firstborn children's ToM understanding before the sibling's birth, their interactions with their infant sibling after the 
birth, and the role of mothers' and fathers' discipline in response to children's misbehavior in predicting ToM understanding a year after the birth. The results yielded insights into how social interactions within the family after the sibling's birth were related to children's ToM development. First, children's ToM before the birth predicted their positive interactions with their infant sibling as early as 4 months after the birth, but did not predict antagonistic interactions at either 4 or 8 months. Initial positive engagement with the infant sibling during the first few months remained stable during the first year. However, positive engagement at 8 months did not predict 12-month ToM, which was somewhat surprising given prior work showing associations between positive, prosocial sibling interactions and ToM (Dunn et al., 1991; Hughes, 2011). One reason may be that positive sibling engagement in these early months is more about approaching and showing a positive interest in the baby, and not the cooperative, fantasy, and joint pretend play that facilitates ToM development (Dunn et al., 1991; Howe et al., 1998). Additionally, prenatal negative reactivity (i.e., children's difficult temperament) predicted increases in sibling antagonism and decreases in positive engagement with the infant from 4 to 8 months. Sibling antagonism at 8 months also negatively predicted ToM at 12 months, but only when mothers used low levels of child-centered discipline in response to children's misbehavior directed at the infant sibling at 8 months. This was not the case, however, when we examined maternal child-centered discipline used at 4 months. A similar moderating effect was found for fathers' 8-month child-centered discipline but did not reach conventional levels of significance. These findings extend our earlier research to demonstrate that the link between children's ToM 
and sibling relationships depended, in part, on how parents responded to children's misbehavior when they interacted with their infant sibling. For young children inexperienced in their first forays with an infant sibling, caregivers' responses to children's interactive attempts may be critical in facilitating children's social understanding. We did not find that parent-centered discipline used at either 4 or 8 months acted as a moderator of the ToM-sibling antagonism link, underscoring it was parents' use of child-centered discipline that really explained whether or not children's antagonistic interactions predicted less ToM understanding.

The literature on sibling relationship quality and ToM suggests there are bidirectional relations between the two, with children's ToM understanding contributing to better sibling relationship quality (e.g., Dunn \& Kendrick, 1982; Hughes \& Ensor, 2005), as well as sibling interactions providing a rich social environment in which young children develop socialcognitive awareness (e.g., Foote $\&$ Holmes-Lonergan, 2003; Perner et al., 1994). Our results also suggest the relations are bidirectional in the first year of siblinghood. For instance, children's ToM before the birth predicted more positive engagement with the infant at 4 months, indicating that advanced ToM understanding had an effect on children's initial positive interest in and engagement with their sibling (Hughes \& Ensor, 2005). Prenatal ToM, however, did not predict sibling antagonism at either 4 or 8 months. In light of previous evidence suggesting that ToM ability may manifest as either a prosocial or antisocial behavior depending on its interaction with different temperamental and contextual characteristics (Ronald, Happé, Hughes, \& Plomin, 2005), future studies would benefit from investigating whether some children use ToM skills to 
avoid conflict while others may deliberately antagonize their infant sibling. On the other hand, sibling antagonism at 8 months negatively predicted children's ToM at 12 months, but this was the case only when mothers used less child-centered discipline. Thus, our results suggest that the relations between sibling interaction and ToM are not only bidirectional in the first year, but also involved complex moderation of family-level processes.

Because of the young age of children when they experience the arrival of their infant sibling, sibling relationships are not mutually interactive in the months immediately following birth. Yet, the mere presence of a sibling in the family may have indirect effects on children's social-cognitive development through the conversations that occur between parents and children about their infant sibling and their behavior toward the sibling (e.g., McAlister \& Peterson, 2007). Children's mental state communications with the caregiver about the sibling's behaviors and desires, and the rules regarding how to interact with an infant sibling can contribute to developing social understanding (Hughes, 2011). In line with this idea, the results from the present study support the key role of mothers' child-centered, inductive discipline in the context of children's misbehaviors towards the sibling for children's social-cognitive growth and the developing sibling relationship. When mothers engage in child-centered discipline, they support children's positive attitudes toward the infant sibling during potential conflict. Similarly, Dunn (1988) argued that the growth of social understanding derives from children's interest in and responsiveness to the behavior and feelings of others. If children frequently engage in antagonistic sibling interactions without their parents' interventions and explanations of the 
social and moral consequences of harmful behaviors directed toward the infant, these children may very well lose the valuable opportunity to advance an understanding of others' feelings and needs, as well as the fundamentals of early moral development. Thus, inductive discipline that involves mental state conversations about the infant sibling with emotionally supportive parents might be essential for children to benefit from the presence of an infant sibling during the transition to siblinghood. It should be underscored, however, that it was only when mothers used child-centered discipline at 8 months, not 4 months, that we found the moderated effects, confirming our hypothesis that the timing of parental discipline may be relevant in understanding the linkages between children's sibling interactions and ToM development. At 4 months after the birth, interactions between children and their infant sibling are not as antagonistic as they are by 8 months (Oh et al., 2015), reducing the likelihood that parents are required to intervene in potential conflict. Only when children are engaging in potential misbehavior with the 8-monthold infant sibling, who is also more socially and motorically adept, did we find the moderating effect of parents' use of child-centered discipline. Our results suggest, then, that not only does the type of discipline seem to matter, but when it is dispensed as well.

Children's negative reactivity predicted higher sibling antagonism at 8 months only when mothers used high levels of child-centered discipline. Perhaps when parents use less childcentered discipline (e.g., forcefully controlling children's behaviors and their access to the infant without inductive strategies), child characteristics are less prominent in predicting sibling relations. Highly reactive children, however, may experience more distress and struggle with 
regulating negative emotions induced by conflict situations. In a previous analysis, we reported that aggression-prone children engaged in higher sibling antagonism and developed poorer ToM during the first year of siblinghood (Song et al., 2016). To help aggressive and reactive children adjust to the transition to siblinghood, it might be particularly important for parents to intervene in antagonistic encounters with the infant sibling using child-centered strategies that include conversations about feelings and thoughts in an emotionally supportive fashion, rather than harsh discipline that punishes the child but does not focus on inner states. We expected punitive, parent-centered discipline would increase sibling antagonism and, in turn, hamper children's social learning from conflict experiences (Foote \& Holmes-Lonergan, 2003; Randell \& Peterson, 2009), but we did not find this to be the case, which may be due to the low-risk nature of our community-based sample of predominantly middle-class, two parent families. Thus, future research may find the moderation effect of parent-centered or harsh discipline in families experiencing more stressors and risks as they undergo the transition following the birth of a sibling.

This study had several strengths. First, the longitudinal design provides insights into the bidirectional processes involved in developing ToM within the family, particularly as it pertains to sibling interaction. A second unique strength of this study was the inclusion of fathers. Fathers may play an informative role for children's adjustment after the transition to siblinghood because of the need for parents to balance the care of two young children, one a newborn infant, and to compensate for the changes that occur in mother-firstborn interactions after the sibling's birth 
(Kreppner et al., 1982; Stewart, 1990). Our results regarding fathers' discipline style were not statistically significant compared to findings with mothers, possibly because mothers were likely to spend more time caring for both children at home during the day when sibling conflict is most likely to occur. However, the effects for the father model were similar with sibling antagonism at 8 months predicting lower ToM understanding at 12 months when fathers used less childcentered discipline. Future studies are clearly needed to test fathers' contributions to children's ToM development and sibling relations in the year following the birth of a sibling. Third, our study examined the transition to siblinghood, which has received little attention in the literature. Given the high stability of sibling relationship quality starting within the month following the birth to the end of the first year (Kendrick \& Dunn, 1982) into preschool (Kramer \& Gottman, 1992), middle childhood (Dunn, Slomkowski, \& Beardsall, 1994) and even into adolescence (Kramer \& Kowal, 2005), more studies may need to examine child- and family-level factors contributing to sibling engagement during the transition to help children build positive sibling relationships.

Despite these strengths, there are also several limitations. Because of our interest in understanding the role of fathers for the transition, participating families were intact two-parent families and mainly middle-class and white, which may limit the generalizability of the findings to children from different family backgrounds. Our findings, however, emerged even after controlling for the influence of several child and family factors, including the child's verbal IQ and parents' education. Second, the measures of children's interactions with their sibling and 
parents' child-centered discipline were drawn from mother- and father-reports. Observations of sibling and parent-child interactions may have yielded a different pattern of findings, although there are potential shortcomings to both self-reports and observational assessments. Whereas parent-reports may suffer from subjective biases, observational assessments are often not long enough to sample low-frequency events such as children's antagonistic or aggressive behaviors.

In the current study, we attempted to deal with these limitations by using multi-informant reports from mothers and fathers, and creating latent factors of children's antagonism and positive engagement with an infant sibling. Future research may benefit by using both parent-reports and observational assessments. Third, the age range of children was relatively wide (i.e., ages 1-5 years) which reflects the fact that parents decide to have their second child at different times following the birth of their first child. Due to the unique characteristics of the current investigation and the overall goal of trying to understand firstborn children's adjustment before and after the birth of a sibling, the time points were established to coincide with the age of the second-born children and not based on the age of the firstborn children. To compensate for the wide age-range and the fact that ToM measures are sensitive to age-related change, we restricted the age range of the firstborns (i.e., 18-47 months at the first time point) and statistically controlled for age in months and verbal IQ in our analyses.

In sum, the present study examined the role of children's earliest interactions with an infant sibling, and both mothers' and fathers' discipline in the development of children's ToM during the year following the transition to siblinghood. Children's social understanding before 
the birth of the infant sibling predicted children's positive engagement with the infant. Children's antagonistic behaviors toward the infant in the first year after the birth predicted children's poorer ToM understanding, but only when mothers (and fathers) used low levels of childcentered discipline. Our findings indicate that child-centered discipline involving communication about emotions and solutions for conflicts during discipline encounters involving the infant is important for ToM development after the arrival of a younger sibling. Future research should be mindful of how mothers and fathers discipline firstborn children following the birth of an infant sibling. Using child-centered discipline that emphasizes other-oriented reasoning and discussions about emotions may enhance the development of young children's social-cognitive understanding and the formation of sibling relationship quality even as early as the first year after the sibling's birth.

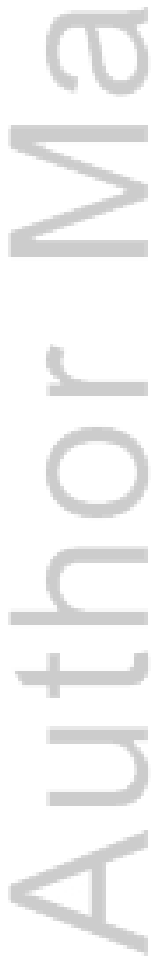

This article is protected by copyright. All rights reserved. 
Table 1

Descriptive Statistics and Correlations between Study Variables $(N=208)$

\begin{tabular}{|c|c|c|c|c|c|c|c|c|c|c|c|c|}
\hline Variable & 1 & 2 & 3 & 4 & 5 & 6 & 7 & 8 & 9 & 10 & 11 & 12 \\
\hline \multicolumn{13}{|l|}{ Prenatal } \\
\hline 1. Child ToM & - & -.02 & -.10 & .05 & .05 & .10 & -.05 & $.13^{\dagger}$ & -.01 & -.02 & -.11 & $.53^{* *}$ \\
\hline 2. Child Negative Reactivity & $.16^{*}$ & $\underline{.55}^{* *}$ & .05 & .06 & $.23^{* *}$ & -.02 & $.21^{*}$ & $.16^{*}$ & $.19^{*}$ & $.13^{\dagger}$ & $.20^{*}$ & .07 \\
\hline \multicolumn{13}{|l|}{$1,4, \& 8$ months } \\
\hline 3. Infant Fussy Temperament (1m) & .05 & .02 & $.55^{* * *}$ & -.12 & -.01 & -.07 & $.17^{*}$ & -.08 & -.08 & -.08 & -.002 & -.11 \\
\hline 4. Positive Engagement (4m) & $.13^{\dagger}$ & -.09 & $\overline{.04}$ & $.42^{* *}$ & .06 & $.65^{* *}$ & $-.16^{*}$ & .02 & -.03 & $.17^{*}$ & -.04 & .01 \\
\hline 5. Antagonism $(4 \mathrm{~m})$ & .07 & $.24^{* *}$ & -.004 & $\overline{.01}$ &.$\underline{47}^{* *}$ & -.02 & $.51^{* *}$ & $.20^{* *}$ & $.50^{* *}$ & $.22^{* *}$ & $.32^{* *}$ & .13 \\
\hline 6. Positive Engagement (8m) & .12 & $-.19^{*}$ & .05 & $.67^{* *}$ &.$\overline{08}$ &.$\underline{.40}^{* *}$ & -.08 & .06 & .02 & $.17^{*}$ & .07 & .05 \\
\hline 7. Antagonism (8m) & -.001 & $.29^{* *}$ & -.03 & -.05 & $.57^{* *}$ & $-\overline{-.01}$ & $\underline{.51}^{* *}$ & .03 & $.41^{* *}$ & $.16^{*}$ & $.54^{* *}$ & .02 \\
\hline 8. Child-centered Discipline (4m) & .04 & .04 & -.06 & $.26^{* *}$ & $.21^{* *}$ & $.20^{* *}$ & $\overline{.11}$ & $.24^{* *}$ & $.42^{* *}$ & $.41^{* *}$ & $.19^{* *}$ & .05 \\
\hline 9. Parent-centered Discipline (4m) & .001 &, 11 & -.06 & .05 & $.50^{* *}$ & .09 & $.32^{* *}$ & .30 & $\underline{.45}^{* *}$ & $.29^{* *}$ & $.57^{* *}$ & .03 \\
\hline 10. Child-centered Discipline (8m) & .04 & .10 & -.04 & $.21^{* *}$ & $.21^{* *}$ & $.14^{\dagger}$ & $.26^{* *}$ & $.58^{* *}$ & $.20 * *$ & $.22^{* *}$ & $.38^{* *}$ & .02 \\
\hline 11. Parent-centered Discipline $(8 \mathrm{~m})$ & $-.21^{* *}$ & $.21^{* * *}$ & -.06 & .06 & $.35^{* *}$ & .12 & $.49^{* *}$ & $.13^{\dagger}$ & $.53^{* *}$ & $.35^{* *}$ & $.35^{* * *}$ & .002 \\
\hline \multicolumn{13}{|l|}{12 months } \\
\hline 12. ToM & $.53^{* *}$ & $.15^{*}$ & -.04 & .12 & .03 & .12 & -.03 & .03 & -.03 & .10 & -.06 & - \\
\hline \multirow[t]{2}{*}{ Father } & .93 & -.74 & 3.74 & 3.63 & 1.62 & 3.64 & 1.92 & 1.75 & 1.56 & 1.90 & 1.65 & 2.46 \\
\hline & .93 & 1.13 & .85 & .62 & .60 & .60 & .61 & .51 & .35 & .49 & .35 & 1.45 \\
\hline \multirow[t]{2}{*}{ Mother } & - & -.79 & 3.59 & 3.80 & 1.65 & 3.85 & 1.98 & 1.85 & 1.67 & 1.96 & 1.74 & - \\
\hline & - & 1.26 & .78 & .65 & .57 & .59 & .65 & .50 & .36 & .51 & .37 & - \\
\hline
\end{tabular}

Note. Except ToM, all variables are reported by both mothers and fathers; $r$ s for mother-reports are presented below the diagonal, father-reports above the diagonal, and cross-parent correlations are reported in the diagonal and underlined.

${ }^{\dagger} p<.10 .{ }^{*} p<.05 .{ }^{* *} p<.01$.

This article is protected by copyright. All rights reserved. 

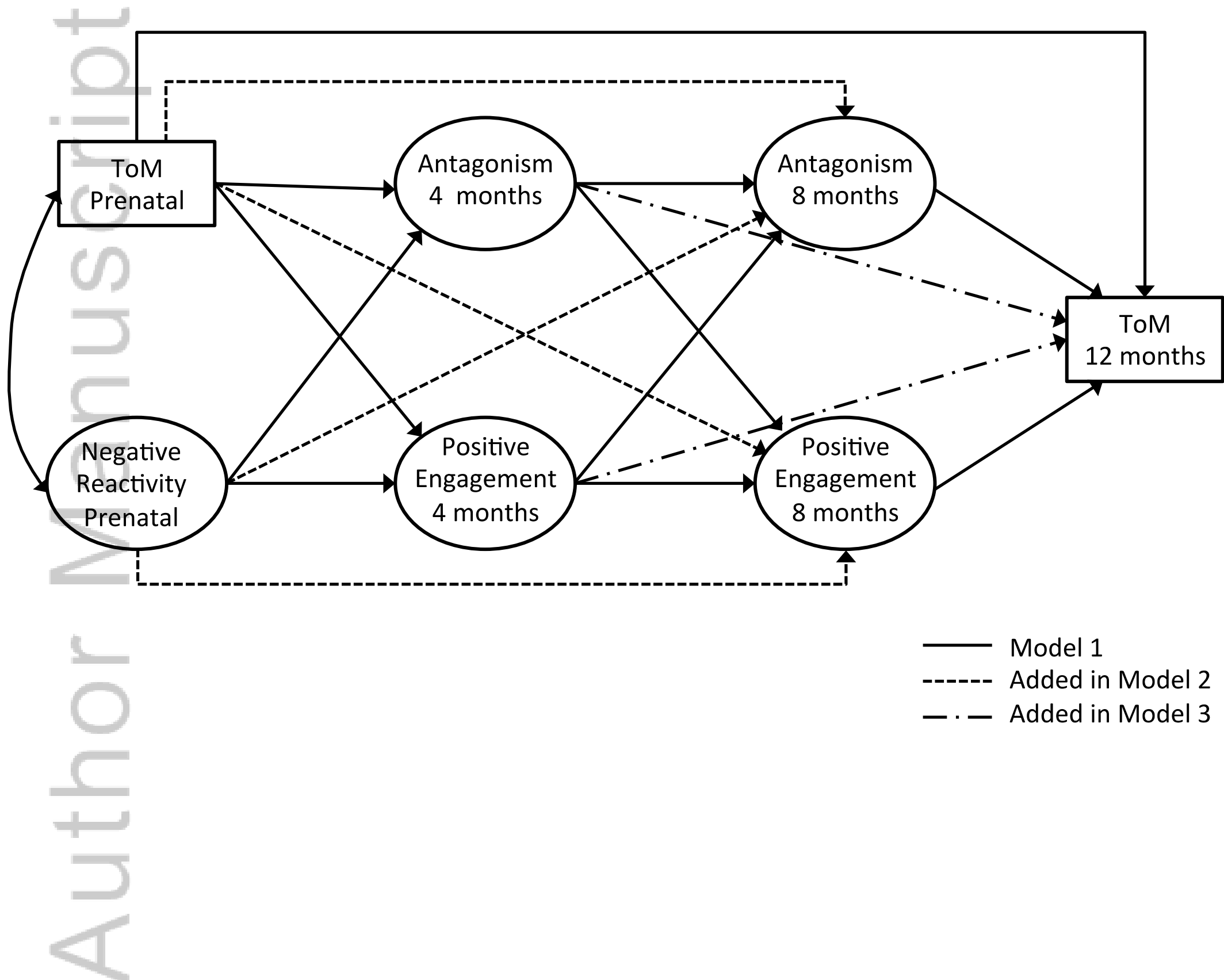

Model 1

------ Added in Model 2

- - Added in Model 3 
Figure 1. Hypothesized models of associations among ToM, negative reactivity, sibling positive engagement and antagonism. Nested models include Model 1 (stability-cross-lag), Model 2 (increasing sibling antagonism and engagement), and Model 3(early sibling influence). All subsequent models contained paths included in the previous model.

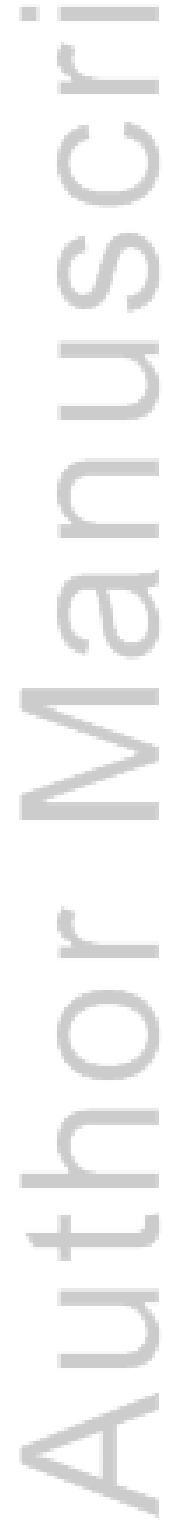

This article is protected by copyright. All rights reserved. 


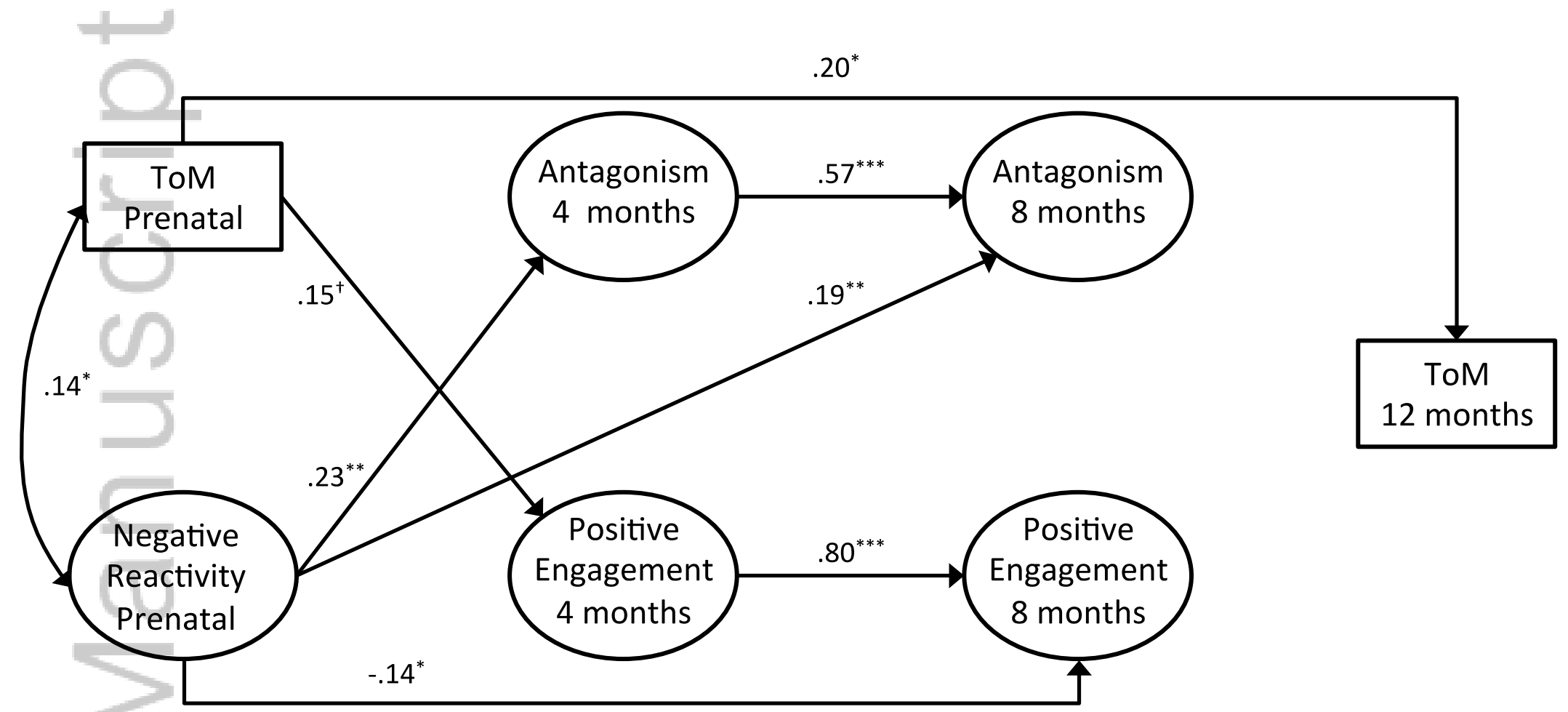

Figure 2. Final model (Model 2) with the full sample examining the relations between Theory-of-Mind and sibling interactions. Significant paths/correlations and those at $p<.10$ are displayed. Non-significant paths/correlations remained in the model. Age, gender, verbal IQ, sibling's fussy-difficult temperament, mothers' and fathers' education were included as covariates but not shown. $\chi^{2}(120, N=208)=167.7, p<.01, \mathrm{CFI}=.95, \mathrm{TLI}=.93, \mathrm{RMSEA}=.04(90 \% \mathrm{CI}=.03-.06)$. ${ }^{\dagger} p<.10 .{ }^{*} p<.05 .{ }^{* *} p<.01 .^{* * *} p<.001$. 


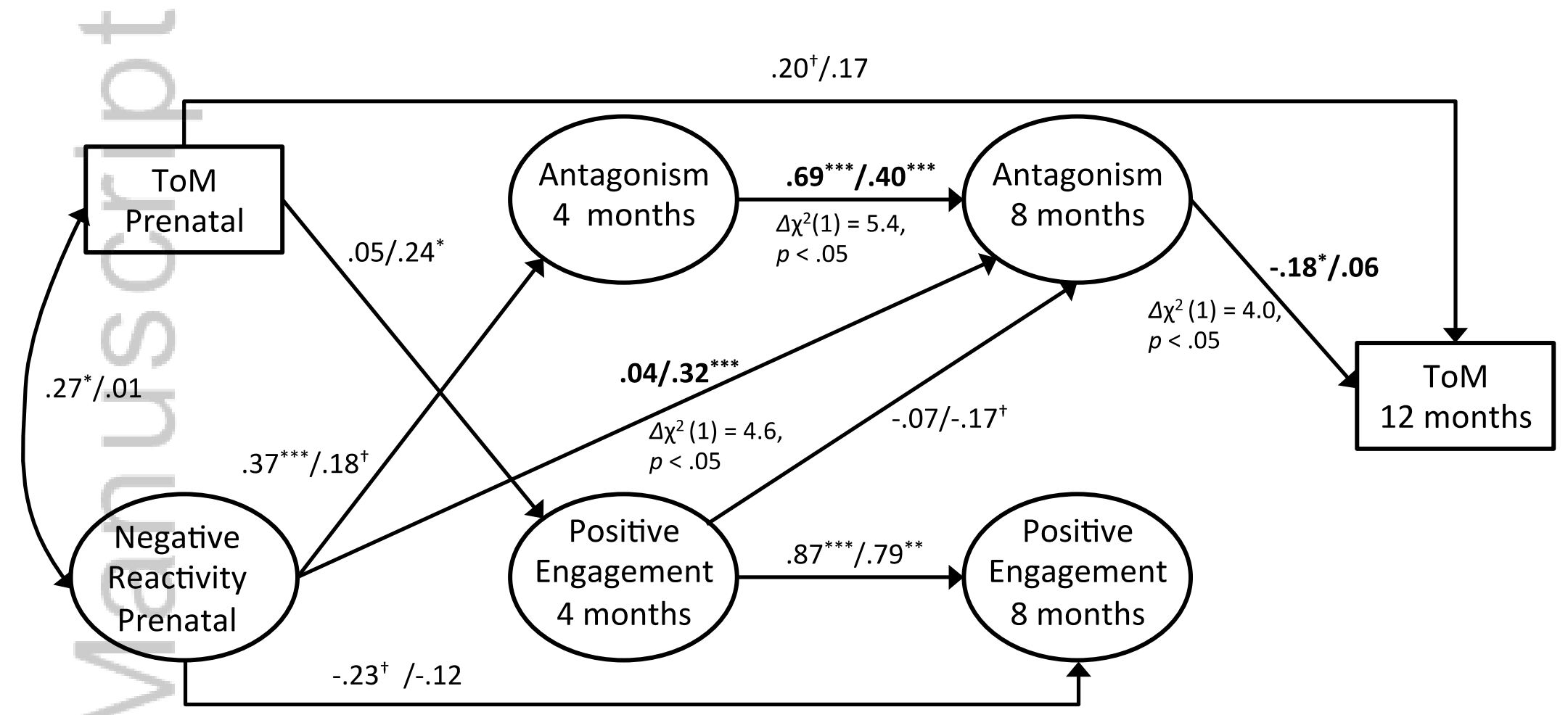

Figure 3. Multi-group analysis with maternal child-centered discipline at 8 months as a moderator, $\Delta \chi^{2}(33)=54.3, p<.05$. Significant paths/correlations and those at $p<.10$ are displayed. Non-significant paths/correlations remained in the model. Bolded numbers and $\Delta \chi^{2}(1)$ values indicate paths that differ between the two groups. Numbers before slashes indicate standardized coefficients for the low child-centered group, and numbers after slashes indicate standardized coefficients for the high child-centered group. Age, gender, verbal IQ, sibling's fussy-difficult temperament, mothers' and fathers' education were included as covariates but not shown.

${ }^{\dagger} p<.10 .^{*} p<.05 .^{* *} p<.01 .^{* * *} p<.001$

This article is protected by copyright. All rights reserved. 


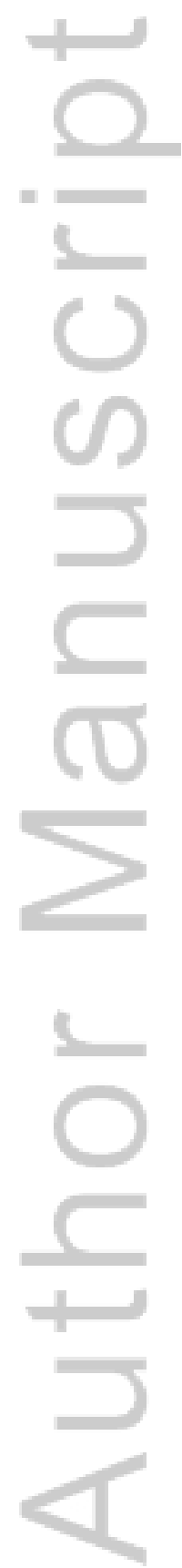

This article is protected by copyright. All rights reserved. 


\section{References}

Adrián, J. E., Clemente, R. A., \& Villanueva, L. (2007). Mothers' use of cognitive state verbs in picture-book reading and the development of children's understanding of mind: A longitudinal study. Child Development, 78, 1052-1067. doi:10.1111/j.14678624.2007.01052.x

Arbuckle J. L. (2013). IBM SPSS Amos 22 User's Guide.

Arnott, B., \& Meins, E. (2007). Links among antenatal attachment representations, postnatal mind-mindedness, and infant attachment security: A preliminary study of mothers and fathers. Bulletin of the Menninger Clinic, 71, 132-149. doi:10.1521/bumc.2007.71.2.132

Baydar, N., Greek, A., \& Brooks-Gunn, J. (1997). A longitudinal study of the effects of the birth of a sibling during the first 6 years of life. Journal of Marriage and the Family, 59, 939956. doi:10.2307/353794

Brody, G. H. (1998). Sibling relationship quality: Its causes and consequences. Annual Review of Psychology, 49, 1-24. doi:10.1146/annurev.psych.49.1.1

Carpendale, J., \& Lewis, C. (2006). How children develop social understanding. Malden: Blackwell Publishing.

Carlson, S.M., \& Moses, L.J. (2001). Individual differences in inhibitory control and children's theory of mind. Child Development, 72, 1032-1053. doi:10.1111/1467-8624.00333

This article is protected by copyright. All rights reserved. 
Cutting, A. L., \& Dunn, J. (1999). Theory of mind, emotion understanding, language, and family background: Individual differences and interrelations. Child Development, 70, 853-865. doi:10.1111/1467-8624.00061

Denham, S. A., Mitchell-Copeland, J., Strandberg, K., Auerbach, S., \& Blair, K. (1997). Parental contributions to preschoolers' emotional competence: Direct and indirect effects. Motivation and Emotion, 21, 65-86. doi:10.1023/A:1024426431247

Dunn, J. (1988). The beginnings of social understanding. Cambridge, MA, US: Harvard University Press.

Dunn, J. (2008). Relationships and children's discovery of the mind. In U. Müller, J. M. Carpendale, N. Budwig, B. W. Sokol (Eds.), Social life and social knowledge: Toward a process account of development (pp. 171-182). New York, NY: Taylor \& Francis Group/Lawrence Erlbaum Associates.

Dunn, J., Brown, J., Slomkowski, C., Tesla, C., \& Youngblade, L. (1991). Young children's understanding of other people's feelings and beliefs: Individual differences and their antecedents. Child Development, 62, 1352-1366. doi:10.2307/1130811

Dunn, J. \&. Kendrick, C. (1982). Siblings: Love, envy and understanding. Cambridge, MA: Harvard University Press.

Dunn, J., Kendrick, C., \& MacNamee, R. (1981). The reaction of first-born children to the birth of a sibling: Mothers' reports. Journal of Child Psychology and Psychiatry, 22, 1-18. doi: 10.1111/j.1469-7610.1981.tb00527.x

This article is protected by copyright. All rights reserved. 
Dunn, J., Slomkowski, C., \& Beardsall, L. (1994). Sibling relationships from the preschool period through middle childhood and early adolescence. Developmental Psychology, 30, 315-324. doi:10.1037/0012-1649.30.3.315

Eisenberg, N., Fabes, R. A., \& Murphy, B. C. (1996). Parents' reactions to children's negative emotions: Relations to children's social competence and comforting behavior. Child Development, 67, 2227-2247. doi:10.2307/1131620

Enders, C. K., \& Bandalos, D. L. (2001). The relative performance of full information maximum likelihood estimation for missing data in structural equation models. Structural Equation Modeling, 8, 430-457. doi:10.1207/S15328007SEM0803_5

Fink, E., Begeer, S., Hunt, C., \& de Rosnay, M. (2014). False-belief understanding and social preference over the first 2 years of school: A longitudinal study. Child Development, 85, 2389-2403. doi: 10.1111/cdev.12302.

Finkel, S. (2004). Cross-Lagged. In Michael S. Lewis-Beck, A. Bryman, \& Tim Futing Liao (Eds.), The SAGE Encyclopedia of Social Science Research Methods. (pp. 229-230). Thousand Oaks, CA: Sage Publications, Inc. doi.org/10.4135/9781412950589.n202

Foote, R. C., \& Holmes-Lonergan, H. A. (2003). Sibling conflict and theory of mind. British Journal of Developmental Psychology, 21, 45-58. doi:10.1348/026151003321164618

Harris, P. L. (2006). Social cognition. In W. Damon, R. M. Lerner, D. Kuhn, \& R. Siegler (Eds.), Handbook of child psychology. Vol. 2: Cognition, perception, and language (6th ed., pp. 811-858). New York, NY: Wiley.

This article is protected by copyright. All rights reserved. 
Howe, N., Petrakos, H., \& Rinaldi, C. M. (1998). 'All the sheeps are dead. He murdered them': Sibling pretense, negotiation, internal state language, and relationship quality. Child Development, 69, 182-191. doi:10.2307/1132079

Hu, L., \& Bentler, P. M. (1999). Cutoff criteria for fit indexes in covariance structure analysis: Conventional criteria versus new alternatives. Structural Equation Modeling, 6, 1-55. doi: http://dx.doi.org/10.1080/10705519909540118

Hughes, C. (2011). Social understanding and social lives: From toddlerhood through to the transition to school. New York, NY, US: Psychology Press.

Hughes, C., \& Ensor, R. (2005). Executive function and theory of mind in 2 year olds: A family affair? Developmental Neuropsychology, 28, 645-668. doi:10.1207/s15326942dn2802_5

Jenkins, J. M., \& Astington, J. W. (1996). Cognitive factors and family structure associated with theory of mind development in young children. Developmental Psychology, 32, 70-78.

doi: $10.1037 / 0012-1649.32 .1 .70$

Jenkins, J. M., Turrell, S. L., Kogushi, Y., Lollis, S., \& Ross, H. S. (2003). A longitudinal investigation of the dynamics of mental state talk in families. Child Development, 74, 905-920. doi:10.1111/1467-8624.00575

Kendrick, C., \& Dunn, J. (1980). Caring for a second baby: Effects on interaction between mother and firstborn. Developmental Psychology, 16, 303-311. doi: 10.1037/00121649.16.4.303

This article is protected by copyright. All rights reserved. 
Kendrick, C., \& Dunn, J. (1982). Protest or pleasure? The response of first-born children to interactions between their mothers and infant siblings. Child Psychology \& Psychiatry \& Allied Disciplines, 23, 117-129. doi:10.1111/j.1469-7610.1982.tb00057.x

Kline, R. B. (2011). Principles and practice of structural equation modeling (3rd ed.). New York, NY, US: Guilford Press.

Kramer, L., \& Gottman, J. M. (1992). Becoming a sibling: 'With a little help from my friends.' Developmental Psychology, 28, 685-699. doi:10.1037/0012-1649.28.4.685

Kramer, L., \& Kowal, A. K. (2005). Sibling relationship quality from birth to adolescence: the enduring contributions of friends. Journal of Family Psychology, 19, 503-511. doi:10.1037/0893-3200.19.4.503

Kreppner, K., Paulsen, S., \& Schuetze, Y. (1982). Infant and family development: From triads to tetrads. Human Development, 25, 373-391. doi:10.1159/000272821

LaBounty, J., Wellman, H. M., Olson, S., Lagattuta, K., \& Liu, D. (2008). Mothers' and fathers' use of internal state talk with their young children. Social Development, 17, 757-775. doi:10.1111/j.1467-9507.2007.00450.x

Lagattuta, K. H., \& Wellman, H. M. (2002). Differences in early parent-child conversations about negative versus positive emotions: Implications for the development of psychological understanding. Developmental Psychology, 38, 564-580. doi: $10.1037 / 0012-1649.38 .4 .564$

This article is protected by copyright. All rights reserved. 
Laranjo, J., Bernier, A., Meins, E., \& Carlson, S. M. (2014). The roles of maternal mindmindedness and infant security of attachment in predicting preschoolers' understanding of visual perspective taking and false belief. Journal of Experimental Child Psychology, 12548-62. doi:10.1016/j.jecp.2014.02.005

Lee, C. S., Lee, J., \& August, G. J. (2011). Financial stress, parental depressive symptoms, parenting practices, and children's externalizing problem behaviors: Underlying processes. Family Relations, 60, 476-490. doi:10.1111/j.1741-3729.2011.00656.x

Lundy, B. L. (2013). Paternal and maternal mind-mindedness and preschoolers' theory of mind: The mediating role of interactional attunement. Social Development, 22, 58-74. doi:10.1111/sode.12009

McAlister, A., \& Peterson, C. (2007). A longitudinal study of child siblings and theory of mind development. Cognitive Development, 22, 258-270. doi: 10.1016/j.cogdev.2006.10.009

McDonald, R. P., \& Ho, M. R. (2002). Principles and practice in reporting structural equation analyses. Psychological Methods, 7, 64-82. doi:10.1037/1082-989X.7.1.64

McElwain, N. L., \& Volling, B. L. (2004). Attachment security and parental sensitivity during infancy: Associations with friendship quality and false-belief understanding at age 4. Journal of Social and Personal Relationships, 21, 639-667. doi:10.1177/0265407504045892

This article is protected by copyright. All rights reserved. 
Oh, W., Volling, B. L., \& Gonzalez, R. (2015). Trajectories of children's social interactions with their infant sibling in the first year: A multidimensional approach. Journal of Family Psychology, 29, 119-129. doi: 10.1037/fam0000051.

Peterson, C. C. (2000). Influence of siblings' perspectives on theory of mind. Cognitive Development, 15, 435-455. doi:10.1016/S0885-2014(01)00040-5

Peterson, C. C., Wellman, H. M., \& Slaughter, V. (2012). The mind behind the message: Advancing theory-of-mind scales for typically developing children, and those with deafness, autism, or Asperger syndrome. Child Development, 83, 469-485. doi: $10.1111 / j .1467-8624.2011 .01728 . x$

Perner, J., Ruffman, T., \& Leekam, S. R. (1994). Theory of mind is contagious: You catch it from your sibs. Child Development, 65, 1228-1238. doi: 10.2307/1131316

Perozynski, L., \& Kramer, L. (1999). Parental beliefs about managing sibling conflict.

Developmental Psychology, 35, 489-499. doi: 10.1037/0012-1649.35.2.489

Randell, A. C., \& Peterson, C. C. (2009). Affective qualities of sibling disputes, mothers' conflict attitudes, and children's theory of mind development. Social Development, 18, 857-874. doi:10.1111/j.1467-9507.2008.00513.x

Ronald, A., Happé, F., Hughes, C., \& Plomin, R. (2005). Nice and nasty theory of mind in preschool children: Nature and nurture. Social Development, 114, 664-684. doi: 10.1111/j.1467-9507.2005.00323.x

Rothbart, M. K., Ahadi, S. A., \& Hershey, K. L. (1994). Temperament and social 
behavior in childhood. Merrill-Palmer Quarterly, 40, 21-39.

Ruffman, T., Perner, J., Naito, M., Parkin, L., \& Clements, W. A. (1998). Older (but not younger) siblings facilitate false belief understanding. Developmental Psychology, 34, 161-174. doi: 10.1037/0012-1649.34.1.161

Slomkowski, C. L., \& Dunn, J. (1992). Arguments and relationships within the family: Differences in young children's disputes with mother and sibling. Developmental Psychology, 28, 919-924. doi:10.1037/0012-1649.28.5.919

Song, J.-H., \& Volling, B. L. (2015). Coparenting and children's temperament predict firstborns' cooperation in the care of an infant sibling. Journal of Family Psychology, 29, 130-135. doi:10.1037/fam0000052

Song, J. -H., Volling, B. L., Lane, J. D., \& Wellman, H. M. (2016). Aggression, sibling antagonism, and Theory-of-Mind during the first year of siblinghood: A developmental cascade model. Child Development, 87, 1250-1263. doi: 10.1111/cdev.12530

Stewart, R. J. (1990). The second child: Family transition and adjustment. Thousand Oaks, CA, US: Sage Publications, Inc.

Vélez, C. E., Wolchik, S. A., Tein, J., \& Sandler, I. (2011). Protecting children from the consequences of divorce: A longitudinal study of the effects of parenting on Children's coping processes. Child Development, 82, 244-257. doi:10.1111/j.14678624.2010.01553.x

This article is protected by copyright. All rights reserved. 
Volling, B. L. (2012). Family transitions following the birth of a sibling: an empirical review of changes in the firstborn's adjustment. Psychological Bulletin, 138, 497-528. doi:10.1037/a0026921

Volling, B. L., \& Belsky, J. (1992). The contribution of mother-child and father-child relationships to the quality of sibling interaction: A longitudinal study. Child Development, 63, 1209-1222. doi:10.1111/j.1467-8624.1992.tb01690.x

Volling, B. L., \& Elins, J. (1998). Family relationships and children's emotional adjustment as correlates of maternal and paternal differential treatment: A replication with toddler and preschool siblings. Child Development, 69, 1640-1656. doi:10.1111/j.14678624.1998.tb06182.x

Wechsler, D. (2002). Wechsler preschool and primary scale of intelligence, Third edition. San Antonio, TX: The Psychological Corporation.

Wellman, H. M. (2014). Making minds: How theory of mind develops. New York, NY, US: Oxford University Press.

Wellman, H. M., Cross, D., \& Watson, J. (2001). Meta-analysis of theory-of-mind development: The truth about false belief. Child Development, 72, 655-684. doi:10.1111/14678624.00304

Wellman, H. M., \& Liu, D. (2004). Scaling of theory-of-mind tasks. Child Development, 75, 523-541. doi:10.1111/j.1467-8624.2004.00691.x

This article is protected by copyright. All rights reserved. 


\section{Footnotes}

${ }^{1}$ For fathers, the omnibus chi-square difference test for 8-month fathers' child-centered discipline approached near significance, $\Delta \chi^{2}(33)=45.8, p<.10$. When probed further, the path from 8-month sibling antagonism to 12-month ToM was significantly different across the high and low child-centered discipline groups, $\Delta \chi^{2}(1)=5.4, p<.05$. Sibling antagonism at 8 months predicted lower 12-month ToM $(\beta=-.12, p<.10)$ in the low paternal child-centered discipline group, but positively $(\beta=.14, p<.10)$ in the high paternal child-centered discipline group. 